\title{
Estratégia Municipal para Qualificação do Comunicação de Informação Hospitalar e Ambulatorial - CIHA
}

\author{
Municipal Strategy for Qualification Information Communication Hospital and \\ Outpatient
}

\section{Elisabete Lira Quelhas Montaño}

Advogada. Gerente de Regulação em Saúde Suplementar. Especialista em Direito da Medicina pela Universidade de Coimbra. Especialista em Gestão de Serviços Públicos de Saúde pela Unifesp. Vinculada a Secretaria de Saúde de São Bernardo do Campo, Brasil.

\section{Renê Contrucci Montaño}

Advogado. Especialista em Direito do Consumo pela Universidade de Coimbra. Vinculado a Ordem dos Advogados do Brasil. Santo André, Brasil.

\section{Angela Santana}

Chefe de Seção de Informação. Especialista em Gestão de Serviços Públicos de Saúde pela Unifesp. Vinculada a Secretaria Municipal de Saúde de Sã Bernardo do Campo, Brasil.

\section{Rosângela Martins}

Gerente da Unidade de Avaliação e Controle. Especialista em Gestão de Serviços Públicos de Saúde pela Unifesp. Vinculada a Secretaria Municipal de Saúde de Sã Bernardo do Campo, Brasil.

\section{Juliana Bonelli}

Enfermeira. Encarregada de Seção do Setor de Informação. Especialista em Gestão de Serviços Públicos de Saúde pela Unifesp. Vinculada a Secretaria Municipal de Saúde de Sã Bernardo do Campo, Brasil.

Resumo: A Comunicação de Informação Hospitalar e Ambulatorial (ClHA) foi criada como instrumento de regulação da assistência à saúde, ao permitir um conhecimento mais abrangente e profundo dos perfis nosológico e epidemiológico da população; da capacidade instalada e do potencial de produção de serviços do conjunto de estabelecimentos de saúde. Todas as unidades de saúde situadas no território 
nacional, públicas e privadas, integrantes ou não do SUS, devem informar ao Ministério da Saúde, por intermédio dos gestores municipais ou estaduais, os atendimentos ambulatoriais e internações que realizam, independente da fonte de remuneração desses serviços. Visando a melhoria da qualidade dessa informação, criou-se um grupo técnico, constituído por representantes de diferentes setores da Secretaria de Saúde de São Bernardo do Campo, que constatou que apenas dois dos 16 serviços privados do município faziam remessa regular de informações, impedindo o conhecimento, pela autoridade sanitária, da morbidade e das causas dos atendimentos naqueles serviços. O artigo descreve a atuação do grupo técnico para reverter a situação, por meio da criação de um espaço de integração entre os setores público e privado e descreve seus primeiro resultados, que incluem o aumento no números de serviços privados que passaram a enviar a CIHA. Demonstra-se a aproximação dos setores público e privado como instrumento de fortalecimento do SUS, ao permitir conhecer melhor os perfis nosológico e epidemiológico da população que utiliza a saúde suplementar.

Palavras-chave: Comunicação de Informação Hospitalar e Ambulatorial, CIHA, Departamento de Informática do SUS.

Key-words: information communication hospital and outpatient; CIHA

\section{Introdução:}

A Comunicação de Informação Hospitalar e Ambulatorial (CIHA) foi criada para ampliar o processo de planejamento, programação, controle, avaliação e regulação da assistência à saúde, permitindo um conhecimento mais abrangente e profundo do perfil nosológico e epidemiológico da população brasileira; da capacidade instalada e do potencial de produção de serviços do conjunto de estabelecimentos de saúde do país.

Embora isso esteja determinado pela Portaria $\mathrm{n}^{\circ} 1.171$, de 19 de maio de 2.011, do Ministério da Saúde, que disciplina que todas as unidades de saúde situadas no território nacional, públicas e privadas, integrantes ou não do SUS, devem informar ao Ministério da Saúde por intermédio dos gestores municipais ou estaduais a ocorrência de todos os atendimentos ambulatoriais e internações, independentemente da fonte de remuneração dos serviços prestados, o serviço privado de saúde tem dificuldade em fornecer as informações.

Referidas informações são de extrema importância, posto que a portaria traz, como sanção, em seu artigo $3^{\circ}$, que, para as unidades não integrantes do SUS, o cumprimento das determinações daquele ato quanto ao envio das CIHA de todos os pacientes, é requisito para a renovação de alvará de funcionamento da Vigilância Sanitária e também para a tramitação de qualquer solicitação ao Ministério da Saúde.

A falta de dados referente à Comunicação de Internação Hospitalar e Ambulatorial no Município de São Bernardo do Campo era algo preocupante na 
medida em que existem dezesseis serviços privados no município - entre eles Pronto-Atendimento, Pronto-Socorro e Hospitais - e nos encontrávamos com um fluxo regular de apenas dois serviços (filantrópicos) fazendo o envio sistemático de ClHA. Ou seja, havíamos perdido o conhecimento do perfil nosológico e epidemiológico dessa população - São Bernardo do Campo tem uma cobertura de saúde suplementar de $60 \%$ da população -, bem como da capacidade instalada, e do potencial de produção de serviços do conjunto de estabelecimentos do município, uma vez que a mudança de $\mathrm{CIH}$ para $\mathrm{CIHA}$ trouxe dificuldades a esses prestadores quanto à adaptação e repasse das informações.

\section{Método}

Visando a melhoria da qualidade da informação da CIHA, bem como de todos os Sistemas do DATASUS, traçou-se a seguinte estratégia, a partir da legislação vigente e do contexto municipal de mais de $60 \%$ de usuários serem cobertos pela saúde suplementar, ou seja, 472.683 beneficiários no município na competência de junho de 2.013 .

Levando tudo isso em consideração o gestor enviou um ofício para cada um dos prestadores privados, com a seguinte redação:

A Secretaria Municipal de Saúde do Município de São Bernardo do Campo entendendo que a informação é base fundamental para a elaboração do planejamento, programação, avaliação e regulação das ações de saúde, preocupada com a inobservância legislativa que determina o envio de $\mathrm{CIHA}$, vem esclarecer o que segue:

A CIHA surgiu da necessidade de incluir, no Sistema $\mathrm{CIH}$, o registro dos atendimentos ambulatoriais não informados no Sistema de Informações Ambulatoriais do SUS (SIA/SUS).

A Comunicação de Informação Hospitalar e Ambulatorial foi criada para ampliar o processo de planejamento, programação, controle, avaliação e regulação da assistência à saúde permitindo um conhecimento mais abrangente e profundo dos perfis nosológico e epidemiológico da população brasileira; da capacidade instalada e do potencial de produção de serviços do conjunto de estabelecimentos de saúde do País.

O sistema permite o acompanhamento das ações e serviços de saúde executados por pessoas naturais ou jurídicas, de direito público ou privado, provendo informações dos pacientes cuja atenção é custeada pelos planos e seguros privados de assistência à saúde;

As informações registradas no sistema servirão também como base para o processo de certificação das entidades beneficentes de 
assistência social para obtenção da isenção das contribuições para seguridade social;

A Portaria $n^{\circ} 1.171$, de 19 de maio de 2.011, alterou a denominação de Internação Hospitalar $(\mathrm{ClH})$ para Comunicação de Informação Hospitalar e Ambulatorial (CIHA), que disciplina em seus artigos $2^{\circ}$ e $3^{\circ}$ conforme segue:

Art. $2^{\circ}$. Fica determinado que todas as unidades de saúde situadas no território nacional, públicas e privadas, integrantes ou não do SUS, devem informar ao Ministério da Saúde, por intermédio dos Gestores Municipais ou Estaduais, a ocorrência de todos os atendimentos ambulatoriais e internações, independente da fonte de remuneração dos serviços prestados.

Art. $3^{\circ}$. Fica estabelecido que para as unidades não integrantes do SUS, o cumprimento das determinações deste ato, quanto ao envio das CIHA de todos os pacientes, devem ser requisito indispensável para a renovação de alvará de funcionamento da Vigilância Sanitária e para tramitação de qualquer solicitação ao Ministério da Saúde.

Ocorre que muitos estabelecimentos não têm realizado o envio dos dados da CIHA em total desconformidade com a Portaria $\mathrm{n}^{\circ}$ 1.171 , de 19 de maio de 2.011 .

Informamos que uma equipe de técnicos da Secretaria Municipal de Saúde entrará em contato com os Serviços Privados para esclarecer dúvidas referentes ao Sistema CIHA, visando facilitar a implantação e remessa mensal do Sistema CIHA a fim de se evitar as punições previstas no artigo $3^{\circ}$, tal qual a não renovação do alvará de funcionamento, o que poderá colocar a unidade de serviço em situação irregular, ensejando a aplicação de outras penalidades decorrentes da falta do respectivo alvará.

A fim de evitar referidos transtornos, contamos com a colaboração de todos no sentido de viabilizar a correta aplicação da norma legal.

Criou-se, na Secretaria Municipal de São Bernardo do Campo, um grupo técnico, como mencionado no ofício, constituído por representantes dos setores de Informação, Saúde Suplementar, Unidade de Controle e Avaliação e Vigilância Sanitária.

Esse grupo criou uma apresentação padrão para todos os serviços, falando que era preciso diminuir a assimetria de informações no setor no intuito de disponibilizar dados de forma objetiva e organizada a fim de auxiliar a tomada de decisões e possibilitar o desenvolvimento de estratégias e inovações que contribuam 
para a construção de um setor suplementar sustentável e o comprometido com a produção da saúde no município. E consequentemente o fortalecimento do SUS.

Muito embora os prestadores de serviços privados não sejam regulados pela Agência Nacional de Saúde Suplementar, alguns prestadores de serviços também são operadoras de planos de saúde, inclusive, com sede no município. Explicamos que uma das funções da ANS é induzir as operadoras a estabelecerem uma nova proposta de atenção mais qualificada, centrada no beneficiário, levando em consideração as especificidades do setor suplementar, ao mesmo tempo em que se alinhe com as políticas empreendidas pelo Ministério da Saúde em todo país. Como, por exemplo, a obrigatoriedade de atualização do Cadastro Nacional de Estabelecimentos de Saúde.

Focamos, primeiramente, no Sistema CIHA, explicando sua importância, obrigatoriedade legal do envio mensal, consequências do não envio. Elaborou-se um cronograma de visitas que ainda vem sendo cumprido. Em cada uma das visitas, esse grupo tentou criar um espaço de integração entre o setor público e o setor privado, visando sempre identificar pares para a continuidade dos serviços.

Era uma queixa muito comum do setor de informação que determinada pessoa era responsável pelo sistema $\mathrm{X}$ e, a certa altura, era desligada da empresa perdendose todo o processo de trabalho; não havia outra pessoa para dar continuidade. Por isso, o cuidado do grupo em identificar seus pares para dar continuidade de forma efetiva em cada serviço.

Solicitamos, nas visitas, a presença de, pelo menos, quem opera os sistemas, um responsável pelo setor de recursos humanos, diretores dos serviços, enfim, todos os técnicos envolvidos na produção da informação, e pactuamos, em cada um desses serviços, que toda a informação nova da Secretaria de Saúde seria disparada por email para todos os envolvidos naquela visita.

Num segundo momento, tentamos fazer com que compreendessem a importância dessas informações no planejamento municipal de saúde, até mesmo, para que fizesse mais sentido a cada um deles, despertando um sentimento de pertencimento a cada uma das informações dos diversos sistemas de informação, em especial, do CIHA.

Após isso, nos colocamos como facilitadores do processo para auxiliá-los a enquadrar seus procedimentos na tabela da Comunicação de Informação Hospitalar e Ambulatorial, estabelecendo de fato uma parceria.

Nesses encontros, aproveitamos para reforçar a importância de outros sistemas, como o Cadastro Nacional de Estabelecimentos de Saúde (CNES), Sistema de Cadastramento de Usuários do SUS (CadSUS), Cartão Nacional de Saúde (CNS), Sistema de Informações e Agravos de Notificação (SINAN), Sistema de 
Informação de Nascidos Vivos (SINASC) e o Sistema de Informações sobre Mortalidade (SIM).

Criamos uma apresentação em PowerPoint, onde construímos uma engrenagem representando os sistemas de informação (Figura 1).

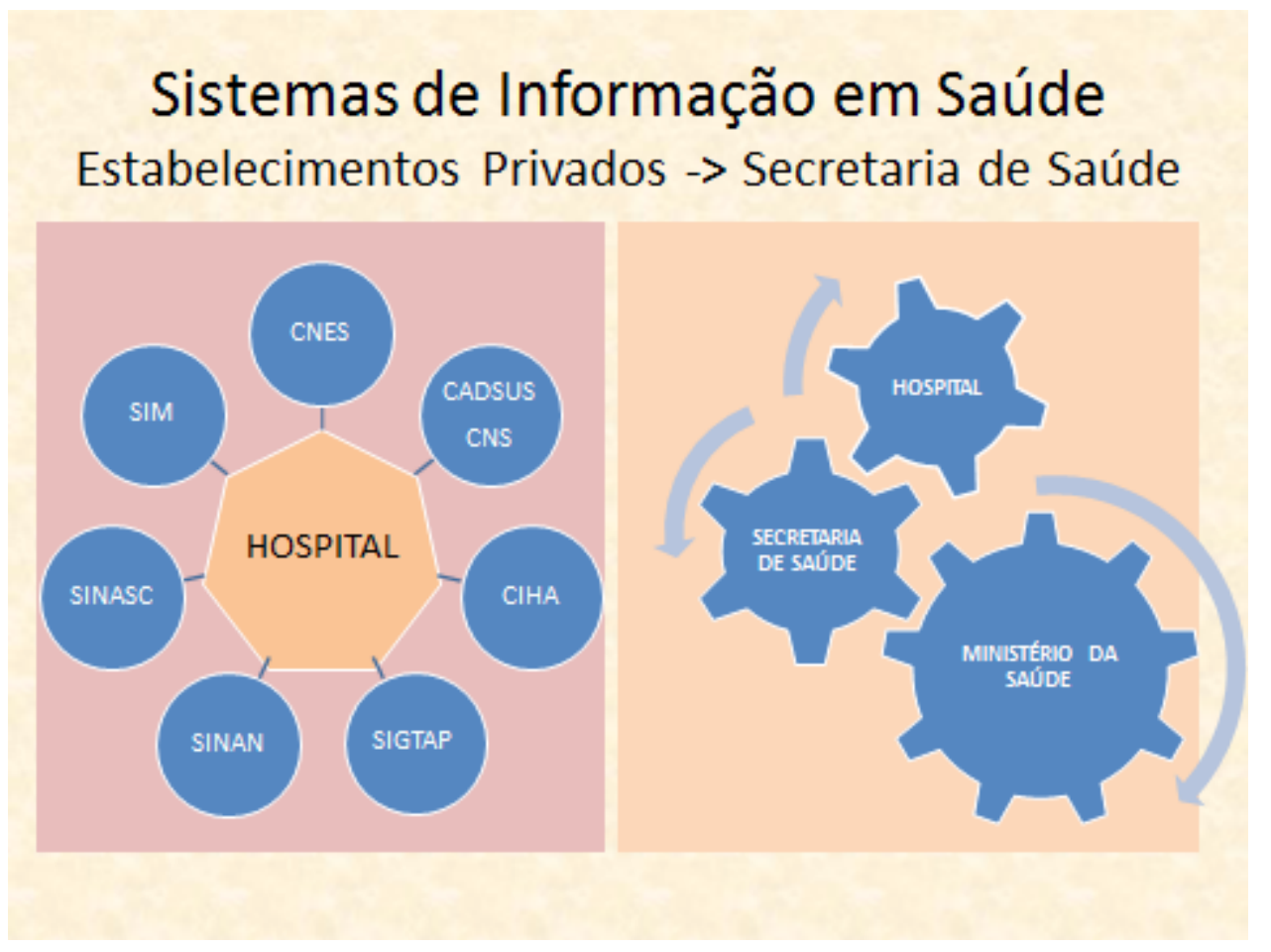

Figura 1 - Sistemas de Informação em Saúde.

Por meio do esquema acima, demonstramos que um hospital deve alimentar diversos sistemas; que a informação deve ser entendida como um todo, ou seja, produzida pelo serviço (hospital) e que esta é integrada pela Secretaria Municipal de Saúde, que, consequentemente, vai integrar o banco de dados do Ministério da Saúde; que essa informação deve funcionar como uma engrenagem para que possa existir um planejamento de ações e serviços de saúde eficazes, onde cada um é responsável por uma parte dessa informação.

São espaços muito ricos para troca de experiências, onde se observa o fortalecimento do SUS no âmbito municipal. Ao término de cada visita é feita uma comunicação à Vigilância Sanitária para que atente, a partir de então, para a questão da renovação do alvará de funcionamento, desde que, o serviço esteja com o fluxo regular do $\mathrm{ClHA}$. 


\section{Resultados}

Estamos ainda em fase de realização das visitas, mas com as primeiras medidas acima elencadas, já sentimos um aumento no número de serviços que estão enviando a CIHA; esses serviços estão nos acionando para tirar dúvidas mais frequentes.

Esse é um processo que demanda o envolvimento de técnicos da Secretaria Municipal de Saúde, dos serviços privados e que se encontra em continuo monitoramento. Os encontros possibilitam aos serviços privados entender como funciona o DATUSUS, que as informações não são ações de preenchimento cartorial para a Secretaria de Saúde, e puderam entender a importância de alimentar os sistemas nacionais, sanar dúvidas e estabelecer novas pactuações como, por exemplo, serviços que estavam com o envio de informações parado há mais de um ano, retomaram no exercício de 2.013 com nosso auxílio, e assim que estiverem dominando o Sistema CIHA, colocarão em dia as remessas anteriores propiciando um maior envolvimento do setor privado a fim de gerar informações fidedignas.

Após a primeira fase, das dezesseis visitas, estenderemos a estratégia para as clínicas de médio e pequeno porte para, de fato, conhecermos a produção ambulatorial dos serviços privados do nosso município.

Essa estratégia demonstra que, quando o setor público se aproxima do setor privado e vice-versa, quem ganha é o Sistema Único de Saúde. No caso em tela, com a apropriação de informações de suma importância que, até pouco tempo, eram impossível obter.

Minimamente, a melhora abrange a atualização do Cadastro Nacional de Estabelecimentos de Saúde, pois muitos serviços apenas replicavam informações, constando como atualizados no sistema, o que não se traduzia, na realidade, no desconhecimento da carga instalada, dos profissionais.

Hoje verificamos que já há um cuidado maior com a informação do CNES, o que acarreta a melhora da qualidade da alimentação do sistema.

Outro Sistema em que obtivemos uma grande melhora foi o Sistema de Informação de Mortalidade (SIM).

Apresentamos a cada um dos serviços um detalhado de quantas certidões foram fornecidas, quantas foram inutilizadas e porque foram inutilizadas. Esse momento foi bem especial, nas visitas, e, a partir de então, tivemos menos rasuras, menos erros nas informações, campos bem preenchidos, que antes passavam desapercebidos.

Em relação ao Sistema de Informação de Nascidos Vivos (SINASC), existem campos que são obrigatórios, mas que os serviços ignoravam, acreditando que eram campos sem importância e, por isso, deixavam de preencher, como, por exemplo, 
Anais dos III Congresso Iberoamericano de Direito Sanitário / II Congresso Brasileiro de Direito Sanitário

profissão e escolaridade. Muitas vezes, o setor de informação precisava devolver o formulário ao serviço para o correto preenchimento, gerando retrabalho para todos.

O que já percebemos uma significativa melhora.

\section{Referência}

Portaria $n^{\circ} 1.171$, de 19 de maio de 2.011, do Ministério da Saúde, que Altera a denominação Comunicação de Internação Hospitalar $(\mathrm{ClH})$ para Comunicação de Informação Hospitalar e Ambulatorial (ClHA). Fonte Ministério da Saúde. 